\title{
Twelve shades of grey: encountering urban colour in the street in British provincial towns, c. | $945-1970$
}

\author{
LUCY FAIRE and DENISE MCHUGH* \\ Vaughan Centre for Lifelong Learning, University of Leicester, Leicester, LE1 \\ 7RH, UK \\ Associate Lecturer, Open University, Walton Hall, Milton Keynes, MK7 6AA, UK
}

\begin{abstract}
This article examines the neglected sensory experience of visual physical colour in the city/town centre or what is now referred to as the Central Business District. It focuses on the post-war period when reconstruction, town planning, new architecture, novel materials and technologies, and investment were all transforming British city centres. The research uses film, photographs, planning documents, oral history and social media reminiscences to research the users' experience of colour in the city centre streets. It argues that, although new materials in construction opened up the possibilities of bright, 'non-natural' colours in the urban built environment, the visual experience of colour was found mainly in the ephemera of everyday life. Furthermore, it argues that colour was an important component in constructing people's sense of place and belonging in the city.
\end{abstract}

\section{Why study urban colour and how to do so?}

Man needs colour to live, it is an element as necessary as water and fire. ${ }^{1}$ Black and white might be sufficient, but why deprive yourself of colour? ${ }^{2}$

Colour is an important component of the historical urban experience as it is central to the physical and visual experience of the street user. The

\footnotetext{
* We would like to thank Dr Neil Raven and Anne McHugh for commenting on early drafts; Dr Miriam Gill for the Hill reference; Colin Hyde, Aaron Andrews, Sally Ann Hartshorne, Dr Malcolm Noble and attendees of the session at the urban history conference at York (2013) for useful suggestions. We are also grateful for the Centre for Urban History at the University of Leicester for providing us with office space over several years which has made our co-writing much easier. Finally, we would like to thank our reviewers for their very helpful and erudite suggestions.

${ }^{1}$ Fernand Léger quoted in J.L. Caivano, 'Research on color in architecture and environmental design: brief history, current developments and possible future', Color Research and Application, 31 (2006), 350-63, at 354.

2 Attributed to the fashion designer Christian Dior who was the inventor of the post-war 'New Look'.
} 
visual experience of physical colour has been part of the urban experience for millennia; research on Pompeii and Herculaneum has revealed the highly coloured and visually rich nature of the built environment of the classical city, while in European medieval cities, the use of colour was highly regulated. ${ }^{3}$ When speaking of urban areas we talk of 'accident blackspots', 'red light districts' or 'green lungs' but academic discussion of colour in towns and cities generally signifies discussion of ethnicity. In this study, we do not examine colour in relation to peoples but rather the manifestation of colour in the material culture of the city centre street, including colour worn on the body.

While the visual experience of city streets is an important one, it is often far behind others in the new sensory historiography which focuses on non-visual senses, in particular smells and sounds. ${ }^{4}$ Our research builds on this existing work, arguing that of all the senses sight is the primary processor of urban impressions and information. Alexander Cowan and Jill Steward have discussed how this powerful visual experience has been manipulated by authorities through the ages in pursuit of agendas of spectacle or order. However, they do not show how this visual encounter was experienced and manipulated by the user. ${ }^{5}$ There is little historical research on colour in the modern city centre: colour is often alluded to as atmosphere, behaviours and transgressions; 'hubbub' or spectacle rather than any discussion of the materiality of physical colour. ${ }^{6}$ An interesting exception is provided by Jessica Jenkins on the architecture of the GDR. She discusses how colour was used by architects to create 'emotional impact' and how it was considered 'to carry ideological value'. 'Studies of urban colour tend to be concerned with the medieval or renaissance city or with issues around heritage and preservation. ${ }^{8}$ In the history of the modern city, physical colour is a neglected topic and the third volume of the Cambridge Urban History of Britain does not mention it in the index. ${ }^{9}$ This omission is partly due to dependence on written sources. The visual sources we use reveal another view of the city permitting us to see colour as part of the everyday visual sensory experience of the city.

${ }^{3}$ J. Gage, Colour and Culture: Practice and Meaning from Antiquity to Abstraction (Berkeley, 1999), 36.

${ }^{4}$ M. Bull and D. Howes, 'The expanding field of sensory studies', The Senses and Society, 11 (2016), 1-2.

5 J. Steward and A. Cowan, 'Introduction', in A. Cowan and J. Steward (eds.), The City and the Senses: Urban Culture since 1500 (Aldershot, 2007), 20-1.

${ }^{6}$ For example R. Sweet, Cities and the Grand Tour: The British in Italy, 1690-1820 (Cambridge, 2013).

7 J. Jenkins, 'A system of joyful colour and its disruptions: architectural colour in the German Democratic Republic', Architectural Theory Review, 19 (2014), 221-42, at 221, 223.

8 P. Hills, Venetian Colour: Marble, Mosaic, Painting and Glass, 1250-1550 (New Haven, 1999); C. Moughtin, O.C. Tanner and S. Tiesdell, Urban Design: Ornament and Decoration, 2nd edn (Oxford, 1999), 142.

9 M. Daunton (ed.), The Cambridge Urban History of Britain, vol. III: 1840-1950 (Cambridge, 2001). 
This article assesses the extent of colour in the exterior urban spaces of the city centre (streets, squares and shopping centres) and where colour was most likely to be found. Importantly, and in contrast to traditional planning history, it examines both the experience and significance of this colour from the user perspective. Veronica Zybaczynski identifies four 'layers' of colour available in the city: first, the 'geographic and climatic layer', in other words landscape and weather; secondly, the built environment; thirdly 'the man-made natural landscape' such as parks or lakes; and, finally, the layer of everyday life including 'the elements related to the auto and pedestrian traffic and all items related to the advertising industry'. ${ }^{10}$ Taking these categories, we demonstrate that this final category, underdeveloped in Zybaczynski's typology, is of the greatest significance in the experience of colour in the city centre. While we have considered colour in relation to all these categories, we argue that colour is mainly found in the further 'layers' of the urban environment as a result of human activity and moveable material culture such as: decorative public art and advertising; signage (including shop fronts); forms of transport (particularly 'buses); and colour on the body (clothing, hair).

\section{Time and place}

Our research focuses on the period when the town centre was still a site of investment as well as a distinctive and highly specialized differentiated space, full of possibility. ${ }^{11}$ The (re)construction of Britain's town centres incorporating innovative ideas, materials, art and colour was made possible by 'the UK's fastest period of sustained growth...from the end of the Second World War up until the early $1970 \mathrm{~s}^{\prime} .{ }^{12}$ A commercial property boom saw an 'unprecedented' increase in activities and valuations in the 1950s. ${ }^{13}$ As a result, the period $1945-70$ was a time when war-damaged cities were reconstructed, largely undamaged city centres were rebuilt and entire new towns emerged. Progressive and fashionable planning ideas produced new urban forms such as pedestrian precincts, highlevel walkways and large-scale building projects. By the end of 1960s and into the early 1970s, however, the pace of transformation in urban centres slowed; a weakening economy and the devaluation of the pound in 1967, followed by restrictions on bank lending, resulted in falling

${ }^{10}$ V.M. Zybacynski, 'Colour-important factors in preserving the local identity', Urbanism. Arhitectura. Constructii, 5 (2014), 87-92, at 88-9.

11 P. Scott, 'The evolution of Britain's urban built environment', in Daunton (ed.), Cambridge Urban History of Britain, 495-524, at 523.

${ }^{12} \mathrm{M}$. Kitson, 'Failure followed by success or success followed by failure? A re-examination of British economic growth since 1949', in R. Floud and P. Johnson (eds.), The Cambridge Economic History of Modern Britain, vol. III: Structural Change and Growth, 1939-2000 (Cambridge, 2004), 27-56, at 31.

13 Scott, 'The evolution of Britain's built environment', 518 . 
investment and failing optimism. Major planned infrastructural projects were cancelled, from William Holford's plan to pedestrianize Piccadilly Circus to the later phases of Cumbernauld town centre. Thus, the period after the war and before devaluation of the pound was a time of optimism and investment in the city centre. ${ }^{14}$

\section{Method}

In order to examine the extent and experience of colour in the urban centre, we have employed a 'bricolage' technique whereby material generated for a variety of reasons is re-purposed to understand previously overlooked or discounted experiences and understandings of the city. ${ }^{15}$ The varied sources we use include still photography, films and TV footage, material culture, advertising in contemporary trade journals such as Architectural Design and the Builder, town plans and reminiscences. By drawing together evidence from these multifarious sources, we reveal the presence and experience of urban colour. These sources shed light on colour in a wide range of post-war town and city centres which are mainly English provincial towns in various states of repair. These towns include: industrial cities such as Sheffield and Birmingham; port towns such as Plymouth and Cardiff; and new towns such as Stevenage, Crawley and Harlow.

The trade journals, through both articles and advertisements, and urban plans allow us to access the possibilities and discourses of colour, rather than the actualities of it. We have accessed the latter via film and reminiscences. Films have been particularly valuable for examining the presence of urban colour and we have used 60 films to identify physical colour in town centres. These films range from official propaganda productions on town planning, to community-made documentaries and private amateur home movies whose backgrounds offer unwitting evidence of colour. Some of these films have been carefully constructed to focus on urban colour such as the 'Look at Life' topicals, while others show random colour caught on film, such as those taken from private-car-mounted cameras driven through cities. ${ }^{16}$ Film makers often went in search of a particular aesthetic: they focused on, and manipulated, scenes in order to produce a particular message. However, despite the

14 The role of economics in city centre change is discussed in another paper: D. McHugh and L. Faire, 'Urban thrills: experiencing structural and technological innovation in post-war city centres', paper presented at the annual Economic History Society Conference, Keele University (UK), Apr. 2018.

${ }^{15}$ L. Abrams and C.G. Brown, A History of Everyday Life in Twentieth-Century Scotland (Edinburgh, 2010), 1.

16 'Look at Life' was a series of films made by the Rank Organisation between 1959 and 1969 focusing on British everyday life. For examples of car-mounted city films, see: 'A Drive around Central Birmingham Early 1950s', www.youtube.com/ watch? $=$ =IGgsrBGjXCA; 'Birmingham Town Centre, 1964', www.youtube.com/watch? v=IFGLNvBMmBo; 'Driving in 1960s Redcar, North of England', www.youtube.com/ watch?v=pOynqr3TLTU, all accessed 21 Jun. 2017. 
colour often being faded or indistinct, except in close-up scenes, film gives us some insight into the nature of colour in the city centre in a broader range of towns and cities and provide us with the street view of colour.

The reminiscence data has been gleaned from community histories, autobiography and open access social media chat websites and discussion boards which are rich with testimony. The advantages and drawbacks of using reminiscences have been well rehearsed in relation to oral history and autobiography but the use of social media and discussion boards has been less discussed. ${ }^{17}$ This form of reminiscent data may be regarded as ephemeral but the value lies in the voluntary nature of the participants' contributions. The anonymous nature of many of these can be a benefit as well as a disadvantage to the historian. While those who use social media are self-selecting, they provide a counterbalance to the autobiographical data because of the short responses required for discussion threads: those who might never write down their memories in full still feel they have something to add. Not surprisingly for memories sites, nostalgia was an underlying discourse: contributors use the sites as an opportunity to regret change in the town centre and marvel at what their town looked like in the past. In common with autobiographies, open access memory and nostalgia websites give us what is often a child's experience of urban colour, recalled in adulthood. While this might skew the data towards a particular cohort, it can still give a different physical perspective on the experience of urban colour. Contributors to Facebook sites and discussion forums are not always clear about what period they are discussing, so we have only used memories which could be situated in time; this did not need to be a specific year but could be pinned down by decade. We use evidence of memories from many individuals, 16 of which feature here.

Our discussion of colour has three main strands. The first considers the possibilities of colour revealed through planning films, plans and trade journals; the second presents the actualities of colour which we have accessed largely through films of towns; and the third strand is the experience of colour and the ways in which people constructed meaning and significance from their encounters with it which we assess using reminiscences.

\section{Colour in the built environment: the possibilities of colour}

In this first strand, we examine how urban planners, architects and the building industry envisaged the use of colour in the reconstruction and redevelopment of post-war towns during the 1950s and 1960s. The main sources used are post-war urban plans, films aimed at planners or about future plans and specialist trade journals on design, building

${ }^{17}$ Blenkinsop is one of the exceptions. L. Blenkinsop, 'The internet: virtual space', in S. Barber and C.M. Peniston-Bird (eds.), History Beyond the Text: A Student's Guide to Approaching Alternative Sources (Abingdon, 2009), 122-35, at 122. 
and architecture. These 'top down' and prescriptive sources demonstrate possibilities of colour in the post-war period that were presented to, and by, planners and architects. The section begins by examining design and trade journals which carried adverts for colourful new building materials. It goes on to assess: colour in planning films from the period; references to colour within planning discourse; and the use of colour in planners' documents.

The development of new materials and paint technologies during the 1950s offered a wide colour choice. ${ }^{18}$ In 1955, an extended British Standard paint range for building exteriors was issued containing 101 colours. ${ }^{19}$ The Builder and Architectural Design advertised new materials, importantly often in colour, indicating the colours available to planners during this period. In July 1956, 'Muroglass' made by Pilkington was advertised in the Journal of Architectural Design as 'the new [sic] coloured glass cladding material'. The glass, which provided both 'protective' and 'decorative' cladding to buildings, came in a range of colours: 'Colours now available are: green, red, grey, yellow, pale blue, deep blue and white. Additional colours are to be added to the range. ${ }^{20}$ A 1958 advertisement in the Builder for Snowcem, an exterior paint, announced 'brighter colours' and a 'new attractive colour range' while 'Decorplast' curtain walling was 'available in a wide range of patterns and colours'. ${ }^{21}$ Ten years previously, Snowcem exterior paint came only in white, cream, pink and silver grey. ${ }^{22}$ In 1963, a Booth Boxrib advertisement claimed that any one of the British Standard range was available but in addition to these tones if you want really unusual colours - just tell us about them. We can make most designer's dreams come true.' However, anyone wanting immediate delivery had a choice of pale blue, light grey, gunmetal and off white. ${ }^{23}$ The latter are described as 'four popular colours' indicating that, despite the huge range of colours on offer, in practice greyer colours were often chosen over brighter tones. The continued dominance of grey was reflected by the fact that the 101 British Standard exterior paint colours had 12 different shades of grey and a few others that could reasonably be considered greyish. ${ }^{24}$

Planning films illustrate how colourful materials could be introduced to the urban environment. The film 'New Town 1959' shows the use of brightly coloured panels of red, yellow and dark blue in Stevenage

18 See Willy Rizzo's photograph of Le Corbusier with a blackboard sketch for a multicoloured building, Paris Match, no. 253, 30 Jan. 1954; C. Yglesias, The Innovative Uses of Materials in Architecture: Landscape, History, Theory and Performance (Jefferson, NC, 2014), 160.

19 British Standard 2660, 1955, Patrick Baty, http://patrickbaty.co.uk/about/book/ bs-2660-1955-smallest-2/, accessed 15 Jun. 2017.

20 Architectural Design, Jul. 1956, 37.

21 'Snowcem' advertisement, Builder, 25 Feb. 1958, 22.

22 'Snowcem' advertisement, Builder, 19 Dec. 1947, 14.

23 'Booth Boxrib' advertisement, Architectural Design, Sep. 1963, 43.

${ }^{24}$ Baty, http://patrickbaty.co.uk/about/book/bs-2660-1955-smallest-2/, accessed 15 Jun. 2017. 
town centre buildings and bright blue bus shelters. ${ }^{25}$ 'The Design of Space' (1966), an instructional film for local authorities and town planners, captured a variety of reconstructed and new town centres including Coventry, Plymouth, Birmingham, Crawley, Cumbernauld and Stevenage. ${ }^{26}$ In this, colour is presented by bright building panels and modern art which was built into the environment as paving, tiling and bespoke display columns for advertising. While older, traditional or less disrupted city centres were shown to have colour, planning films concentrated on different, usually brighter, colour found in new towns. ${ }^{27}$

However, despite the fact the period saw the emergence of brightly coloured building materials, references to specific colours in films and post-war planning discourse were rare. Any choices of colour in planning and architecture were hardly articulated. A small movement of architects, notably influenced by Amédée Ozenfant, attempted to systemize the use of colours used in and on buildings and in planning schemes. While these largely affected public buildings such as schools and hospitals, they were influential in producing the British Standard paints from $1955 .^{28}$ This lack of interest in named colours contrasted with Jenkins' findings for GDR architecture during the post-war period. Here, specific colours were employed to articulate particular meanings such as 'joy in life' or to encourage happiness in socialism; as the East German architects changed their influences between 1950s and 1970s, so too did their colour choices. ${ }^{29}$ In post-war Britain, discussion of colour in relation to exterior urban space was usually articulated through vague terms such as 'brightness' and 'attractive' which were contrasted with the dreary pre-war town. A 1959 new towns exhibition catalogue, produced by the Town and Country Planning Association together with 15 new town corporations, described Queen's Square, Crawley, in the following terms:

The new centre is Queen's Square, with its broad pavements and fine buildings, housing many of the most famous stores in the kingdom. It has been adorned with a bandstand, used regularly for performances of local bands, fountain and sculptures, mosaics and flower kiosk. With a changing display of flowers set off against selected trees, and thronged with shoppers, it now forms one of the gayest and most successful shopping centres of the southern counties, drawing customers from a wide radius. ${ }^{30}$

25 British Pathé, 'New Town 1959'; YouTube, accessed 5 Jul. 2017.

26 East Anglian Film Archive (EAFA), 'The Design of Space' (1966), catalogue no. 6067.

${ }^{27}$ See, for example, a wintery Cardiff in British Pathé, 'Centre 70 AKA City of Cardiff' (1970), or Leicester city centre shown in the amateur film 'Leicester Bus Archive', YouTube www. youtube.com/watch?v=TG5RYP2IIUU, accessed 14 Dec. 2016, compared to British Pathé, 'New Town 1959', film ID 93.17, 0.16.

28 T.W. Allan Whitfield, 'The men who coloured Britain', Color Research Application, 30 (2014), $535-9$.

29 Jenkins, 'A system of joyful colour', 224, 231.

30 Town and Country Planning Association with 15 New Town Development Corporations, New Towns: An Exhibition Arranged by the Town and Country Planning Association and Fifteen New Town Development Corporations 3-17 October 1959 (London, 1959), 16. 
This multicoloured square is inferred only through the term 'gayest' and we are left to imagine the colour of the flowers and the green of the trees in the black and white image beside the text. The 1959 film of Stevenage asserts that in Stevenage town centre 'wherever one turns, the outlook is gay and eye-catching' and the town was praised for the innovative 'continental style kiosks with their colourful posters'. ${ }^{31}$ The commentator makes no specific reference to the choice of red and yellow glass panels in the main shopping precinct. The one exception to the general lack of reference to specific colour was green which was mentioned in connection with green belts or, of relevance to the city centre specifically, 'greens'. ${ }^{32}$ In general, however, greenness was implied through description of parks and open spaces, rather than being specially labelled as 'green'.

'Brightness' was considered an important feature of modernity which was enhanced by comparison with the industrial grime of the nineteenthcentury and early twentieth-century town. The 1943 film 'Development of the English Town' emphasized the greyness and dirty dinginess of the pre-war cities, promising that planned and reconstructed towns would bring 'beauty, efficiency, good living and safety' in clean environments. ${ }^{33}$ 'Charley in New Town' (1948), a government propaganda colour cartoon film made to promote town planning, also highlighted the impact of decades of industrial pollution on the colourings of a town and city. The film portrayed the pre-war town blackened by industrialization which was then contrasted with planned future new towns as predominantly red and green in tone with clear skies, 'flower gardens' and an 'attractive town centre'. ${ }^{34}$ In the influential report, Traffic in Towns (1963), the sketches with their bright accents of colour contrasted with the monochrome photographs and, perhaps unintentionally, reinforced the discourse of colourful modernity against the chaos and drabness of the Victorian town. ${ }^{35}$ The discourse of pre-war grime contrasting with modern brightness was also used by the public in response to urban improvements. The link between modernity and colour was made implicitly in a 1953 letter from B. Martin of Coventry regarding the newly installed Lady Godiva Clock: 'I am sick of letters criticising the Broadgate clock. What had we in old Coventry but dirty streets, drab tramcars, and many other defects / / Now at last we are becoming an up-to-date city. We have a place we can be proud of. ${ }^{36}$ Another letter comments: 'I like the idea of the Godiva clock with its figures of Godiva and Peeping Tom. And

31 British Pathé, 'New Town 1959', 0:47; 0:57.

32 For example British Film Institute (BFI), 'Charley in New Town', Central Office of Information, 1948, BFI ID 20691, 8.14.

33 British Council Film Collection, 'Development of the English Town' (1943), 15:38.

34 BFI, 'Charley in New Town', 5.48, 5.56.

35 C. Buchanan, Traffic in Towns: A Study of the Long-Term Problems of Traffic in Urban Areas (London, 1963).

36 B. Martin to Coventry Evening Telegraph, 27 May 1953. 
I like the statue in the middle of the Broadgate Island. They make the city brighter. ${ }^{37}$

The lack of precision regarding colour was reflected in post-war town and city plans. Many of the drawings were monochrome: fully coloured plans were rare. ${ }^{38}$ Plans that were in colour had a limited palate which often consisted of primary or bright tones that were broadly impressionistic rather than realistic colour schemes. In Traffic in Towns and the Leicester Traffic Plan (1964), the colours were bright red, green and blue. ${ }^{39}$ Larkham and Lilley have noted this 'striking and colourful imagery' of town plans, but neither they nor the planners explained the significance of the choices of colour that did emerge in the built town. ${ }^{40}$

Although the modernist movement in Europe produced colourful buildings as part of the 'Call to Colourful Building' following World War I, British modernist architecture in the inter-war and post-war periods tended towards the white minimalist or neoclassical building. ${ }^{41}$ Street, discussing the 1951 Festival of Britain, argues that 'vibrant colour was seen as the natural choice to express the festival's utopian aspirations' but in the main the colouring of town plans reflected a pre-war pattern. ${ }^{42}$ An image of a pedestrianized street in the Leicester Traffic Plan had buildings depicted as grey or white; colour is brought to the city streets by shop signs, floral displays, trees and people's clothing. ${ }^{43}$ The colour in Traffic in Towns followed a similar pattern: buildings and streets surfaces are in black and white while trees are coloured green and the odd item of clothing is picked out. For example in an impression of a proposal for the market square in Newbury, a woman's head scarf and a butcher's apron are tinted mid-blue and a man's jumper is the same green as the trees and market stall 'valance'. The only other features coloured are the canopies to market stalls (all three colours) and the shop signs (blue and red). In an impression of a suggested redevelopment of London's West End, again, cars and buses are blue, green and red, and signs, trees and the occasional person are picked out with colour. However, the buildings and the road are depicted in grey and black. ${ }^{44}$

37 Alma Wood to Coventry Evening Telegraph, 15 May 1953, 8.

38 P.J. Larkham, 'Selling the future city', in Iain Boyd Whyte (ed.), Man-Made Future: Planning, Education and Design in Mid-Twentieth-Century Britain (Abingdon, 2006), 99-120, at 106.

39 Buchanan, Traffic in Towns; W.K. Smigielski, Leicester Traffic Plan: Report on Traffic and Urban Policy (Leicester, 1964).

40 P.J. Larkham and K.D. Lilley, 'Plans, planners and city images: place promotion and civic boosterism in British reconstruction planning', Urban History, 30 (2003), 183-205, at 183.

41 W. Whyte, 'The Englishness of English architecture: modernism and the making of a national international style, 1927-1957', Journal of British Studies, 48 (2009), 442-65; Jenkins, 'A system of joyful colour', 222.

42 S. Street, 'Cinema, colour and the Festival of Britain, 1951', Visual Culture in Britain, 13 (2012), 83-99, at 85.

43 Kenneth Brown illustrator, 'Gallowtree Gate: suggested transformation into a pedestrian shopping street', Leicester Traffic Plan, illustration 160.

44 Buchanan, Traffic in Towns, 78 figure 98, 143 figure 186. 
While new, brightly coloured building materials became available, architects and planners mainly continued to employ more neutral tones in their designs. There is little specific reference to choices of colour, the latter mainly being articulated through terms such as 'bright'. Consequently, in planners' representations of the renovated town, colour is represented by human activity and moveable material culture rather than from the built environment. As we shall see, this reflected accurately the actual experience of colour in towns.

\section{Where was the colour?}

This second strand examines what colour was found in the city centre in the post-war period and how environmental conditions such as climate, industry and air quality had an impact on the tone and preservation of colour within towns and cities. We also examine which forms of material culture were most likely to bring colour to the town and city centre. The main sources are various forms of film including documentary, amateur and topical films. Films give an indication of the colours present in the town or city: the bright bus in the dingy street; flashes of passing advertising; the coloured clothing moving across the screen. They offer us 'dynamic representations as opposed to passive illustrations' of the city. ${ }^{45}$ However, as with any source, film has its limitations. The quality of the original film and its state of preservation has an impact on colour with 'close ups' providing more distinct colour than long-distant shots, where colour is 'washed out'. Films are also limited by their focus on select subject matters, such as new towns and open markets. To mitigate this, we have examined extant material culture, in the form of buildings and their decoration, to reveal colour in towns. This is mainly found in the upper sections of buildings, as street furniture, shop signs and road surfaces from the period, so important to the experience of colour, have long gone. Identifying the original colours of buildings while 'walking the landscape' can be difficult. Even those with their original colours often have faded from their initial glory over time. ${ }^{46}$ However, seeing the buildings 'in the flesh' reveals colourful details, such as tiles or ornaments, or show subtleties of tone which are suppressed in panoramic shots of urban streets.

Despite the discourse around colour and modernity in this period, the built environment of most city centres remained largely monotone or neutral. Films reveal that on the whole older towns were not intrinsically colourful in their architecture and environment and, in the decades following the war, Britain's cities were coloured with dark and dull tones. Films of Stourbridge, Birmingham and St Albans town centres all highlight the lack of colour in the older urban environment with only the painted

\footnotetext{
45 L. Nead, 'Animating the everyday: London on camera circa 1900', Journal of British Studies, 43 (2004), 65-90, at 66.

46 P. Riden, Local History: A Handbook for Beginners (London, 1983), 45.
} 
shopfronts, vehicles and pedestrians adding colour to the urban scene. ${ }^{47}$ A 1964 film of the Bull Ring featured colour in shots of flowerbeds, transport, clothing, signage and the market and inside the shopping centre by the shopfronts, lights, the clothing of shoppers and the indoor parasols of a café bar. The modern built environment was comprised of various shades of grey; colour was provided by traditional urban features. ${ }^{48}$ Even the centres of new towns could be less than colourful; an early colour film of Basildon new town centre in 1963 showed modern concrete and brick monochrome buildings albeit enlivened with large colourful abstract mosaics in mainly primary colours. Other colour was provided by shop signs, grassed areas, the clothes of the people in the pedestrian precinct and by the traffic on the road at the end of the pedestrian zone. ${ }^{49}$

Air pollution in town and city centres had an impact on the experience of colour in relation both to the perception of shade and the intensity of tone. To be urban was, to some extent, to be and to experience grey. In many town and city centres, the monochrome visual landscape resulted from the urban environmental conditions: buildings were blackened from decades of soot and pollution. In addition, buildings remained shabby from a lack of wartime maintenance and material shortages. Architectural historian Andrew Crompton comments: 'It's fair to say Manchester was the filthiest city in the world and the point of maximum blackness was in the late 1940s. All the buildings were blanketed in soot and even the streets were black. ${ }^{50}$ Buildings, paint colours and clothing were discoloured; decorative features and even functional colours were muddied, losing clarity and identity due to dirt and pollution. Leicester's railway station is a good example: today its red and yellow brick, yellow stone and gold and red signage is clearly visible in the landscape but during the period covered by this article, it was dulled by a layer of soot and urban pollution. ${ }^{51}$ The weather also took its toll on the colours in the city: Derrick Buttress described how the white Portland stone of Nottingham's Council House turned to a 'dirty grey' in the 'winter rain'. ${ }^{52}$ The legacy of a grime-darkened environment was compounded by a series of poor-quality air events which started in 1948 with foggy weather and culminated in

47 'Stourbridge Town Centre in the 1960s', YouTube www.youtube.com/watch?v= IFGLNvBMmBo, accessed 17 May 2017; 'Birmingham Town Centre 1964', YouTube www. youtube.com/watch? $\mathrm{v}=\mathrm{IFGLNvBMmBo,} \mathrm{accessed} 17$ May 2017; 'Look at Life, New Roads for Old, 1959', YouTube www.youtube.com/watch?v=bLaRH67dApI, accessed 17 May 2017.

48 'Old Bullring Clip 1' (1964), YouTube www.youtube.com/watch?v=B_Wphod3v4o, accessed 5 Jul. 2017.

49 'Basildon Town Centre circa 1963', YouTube www.youtube.com/watch?v= qez0w6MfF3Q, accessed 27 Apr. 2017.

50 P. Gallagher, 'Manchester's dark history: archive pictures show the city's blackened landmark buildings before the Clean Air Act', Manchester Evening News, 5 Mar. 2016.

51 Channel Four News, Immigration Archive: 'Ugandan Asians in Leicester' (1972), www. channel4.com/news/immigration-archive-ugandan-asians-in-leicester-1972, 1:40.

52 D. Buttress, 'Market Square memories', in J. Walker and P. Fillingham (eds.), The Sillitoe Trail Factory Handbook (Nottingham, 2012), 6. 
the great London smog of $1952 .{ }^{53}$ 'Smog', the damp, greasy sulphurous air polluted with coal particles, regularly settled over London and other British cities in certain weathers. ${ }^{54}$ Smog was a killer which transformed environments from familiar reassuring places into strange, invisible, isolating experiences. When smog seeped indoors in theatres or even Whitehall departments, it impacted dramatically on vision. ${ }^{55}$ This impact on visibility is recalled on Birmingham message boards:

I remember them in the 50's and 60's [sic] quite vividly. They were not so bad when they came down as a white mist and we kids thought they were great, ideal conditions for hide and seek. It was when they came down as a yellow smog. ${ }^{56}$

People remembered how landmarks and colours disappeared as visibility reduced street users to new strategies:

I recall one evening as a lad leaving the Odeon cinema in the city and joining a queue in Corporation Street for my bus home. Had to walk past the line to check the bus sign to ensure I was going to be joining the correct bus queue. One could barely make out the tall street lamps above and the illumination of the front of a shop opposite just gave a dull glow. ${ }^{57}$

Even after the introduction of the Clean Air Act in 1956, improvement was slow. In Birmingham, Paul Stacey remembers: 'the pea soupers we had in the late 50's early 60's [sic], one night my dad and me came out of the Royalty Harborne and it was so thick you couldn't see the bus stop' ${ }^{\prime}{ }^{5}$

The British climate also had an impact on the intensity of colour and decoration in the urban landscape as images of Preston's St George's Shopping Centre clearly show. Like many of the new town shopping precincts, the structure and colours of Preston's shopping centre seemed to presume a Mediterranean climate with the precinct design exposing décor and shoppers to all weathers. Originally built in 1966 as a twostorey open-air rotunda, early film and postcards show the upper face of the inner ring decorated with bright, primary coloured three-dimensional abstract shapes on a white background. Later photographs show these to have weathered and faded into almost pastel tones. ${ }^{59}$ This washing

${ }^{53}$ B.W. Clapp, An Environmental History of Britain since the Industrial Revolution (London, 1994), 44.

54 P. Hennessy, Having it so Good: Britain in the Fifties (London, 2006), 120.

55 Ibid., 120; Clapp, An Environmental History of Britain, 44.

56 'Phil', 'Pea Souper Fog in Brum', Birmingham Forum www.birminghamforum.co.uk/ index.php?topic=364.5; wap2, accessed 26 Apr. 2017.

57 'A. Willoughby', 'The Smog', Birmingham History Forum http://birminghamhistory.co. uk/forum/index.php?threads/the-smog.9070/, accessed 26 Apr. 2017.

58 Paul Stacey, 'Birmingham Fog', Birmingham History Forum https: / / birminghamhistory. co.uk/forum/index.php?threads/birmingham-fog.10692/\#post-74041, accessed 8 Feb. 2017.

59 'Preston, Lancashire 1969', YouTube www.youtube.com/watch?v=z-ETOFDpFOE, accessed 27 Mar. 2017; Flickr www.flickr.com/photos/rpsmithbarney/4879523547/in/ photostream/; Blog Preston, www.blogpreston.co.uk/2015/05/nostalgic-1960s70spreston-revealed-in-pictures-part-2/, accessed 27 Mar. 2017. Both the Twentieth Century 
out of colour also applied to the non-built environment. Two colour films of Hull, one made in 1959 and the other in the late 1960s, feature buses which are apparently navy blue with cream stripes. ${ }^{60}$ However, a collection of photographs on bus enthusiasts' websites confirm that the Hull corporation bus livery was actually blue (close to Pantone Airforce blue) and white, colours that were not obvious, or could not be maintained, in the urban atmosphere. ${ }^{61}$ ' $\mathrm{Rob}^{\prime}$ remembered that the maroon and cream of the Leicester corporation buses were 'Smart and classy when freshly painted, as on a new bus, but after a year or two, a dirty brown and offwhite. $^{62}$ The urban environment could also cause problems with wearing some colours. Pam Inder went to university in Manchester in 1962 packing '[t]wo "sloppy Joe" heavy knit sweaters - one yellow "V" neck (impossible to keep clean in pre-smokeless fuel Manchester, so seldom worn)' and one emerald green with a polo neck. ${ }^{63}$ Mary Essinger, while a trainee fashion designer, was told 'on the grimy platform at Leicester' her gold duster coat was unsuitable for a work trip to central London: 'That's a ridiculous colour for a train journey. ${ }^{64}$ As these examples show, paler colours like yellow were particularly prone to discolouration in the urban environment.

If there was not a predominance of colour in the built environment of this period, where did colour appear in the city centre? Film sources highlight the impact of commercial signage, advertising, traffic controls, buses and clothing in bringing colour to the urban landscape. From the perspective of the camera, we get a street user's view of urban colour. Against a drab, dirty and often wet background, only vibrant and brighter colours stood out, and in colour films and photographs of city centres, transport is often one of the most colourful components of urban life. An example is a 1963 British Transport film short documentary promoting bus use in towns, where colour in the urban landscape comes from clothes and vehicles, echoing the town plans discussed above. ${ }^{65}$ The buses

Society and Pearson have noted the vulnerability of murals and mosaics; 'C20 Society Murals Campaign', https://c20society.org.uk/murals-campaign/, accessed 5 Jul. 2017; L. Pearson, Public Art 1945-95: Introductions to Heritage Assets (London, 2016), 16.

60 'Hull 1959', YouTube www.youtube.com/watch?v=5zqXhHFTJUY, accessed 7 Feb. 2017; 'A Day at Hull - A Cine Film Made in the 1960s by the Late Stan Wilson', YouTube www. youtube.com/watch?v=B9qUPVGa-Wc, accessed 7 Feb. 2017.

61 'Old Bus Photos' www.old-bus-photos.co.uk/?cat=53, accessed 8 Feb. 2017; 'Mike's Bus Pages' www.mikesbuspages.com/municipalbuses.htm, accessed 8 Feb. 2017.

62 Rob Haywood, 'On the Buses - Early Days', Rob and Val Haywood of Leicestershire and Hull www.rhaywood.karoo.net/personal/buses/busmemories.html, accessed 25 Jan. 2017.

63 Pam Inder, '1962 Dress Memories', clothes tell stories: working with costumes in museums www.clothestellstories.com/index.php/telling-stories-with-clothes/1962dress-memories\#childhood, accessed 12 Oct. 2016.

${ }^{64}$ M. Essinger, In My Fashion: Starting Work in the Heyday of Leicester's Knitwear Factories (Loughborough, 2005), 52.

65 BFI, 'Omnibus for All' (1963), YouTube www.youtube.com/watch?v=zS11ovLr3xM, accessed 18 Jan. 2017. 
themselves and the advertisements they carried, particularly for soap powders and bars 'for colour', are often the brightest part of the street scene. ${ }^{66}$

Films also show the splashes of colour produced by traffic control furniture such as traffic lights, Belisha Beacons on crossings (lit from 1948) and internally illuminated bollards (from the 1930s). These brought brightness to the urban scene and are comparable in their visual impact to the illuminated advertising with coloured and neon lighting. ${ }^{67}$ Neon lights brought both light and colour to the city. They had appeared pre-war, but by the 1950 s were being used in wider and more creative ways. ${ }^{68}$ In an online discussion about 1950s Nottingham, 'Trevor' recalled a neon sign which 'was coloured, in the shape of a Martini glass which was slowly filled up and when full, coloured bubbles went up in all directions. This repeated itself and I think it may have been for Schweppes? Anybody remember that??'69 Another contributor 'Ashley' did remember it in the early 1960s: 'Think that neon sign was red and yellow?'70 Advertising and signage also contributed to light and colour in the city centre on dark days or at night. New materials and technologies resulted in lit shop signs and fascia but also in mobile displays. In 1961, Imperial Chemicals were advertising illuminated perspex advertising panels for bus sides: 'Bright, colourful, backed by florescent lighting, the signs are really easy to read on the darkest night. ${ }^{71}$

As part of the 'constructed environment', new shopping precincts and centres often incorporated trees, flower beds and planters to soften the landscaping which added natural colour to the urban landscape. "The Design of Space' film for planners (1966) emphasized the importance of bringing 'the countryside right into the town' and showed how, in Stevenage New Town, mature trees were incorporated into the shopping precincts. ${ }^{72}$ Under the 1947 Town and Country Planning Act, it had become possible to protect existing urban trees with a tree protection order. The film also featured the planting of central reservations with trees and concrete flower beds to green Birmingham's city motorways which were visible from the Bull Ring. ${ }^{73}$ Such planting did not always induce cheer in locals; new town Hemel Hempstead had a city centre road with a reservation 'punctuated by narrow, raised concrete flower

${ }^{66}$ Ibid., 2:16.

67 Media Archive Central England (MACE), 'Know your Midlands: Nottingham by Night', broadcast 19 Aug. 1957.

68 C. Ribbat, Flickering Light: A History of Neon (London, 2013), 42.

69 'Trevor', 'London Road', Nottsalgia.com, https://nottstalgia.com/forums/topic/ 9787-london-road/\#comment-128849, accessed 27 Apr. 2017.

70 'Ashley', ibid.

71 Imperial Chemicals advertisement, Design, 156 (1961), 33.

72 See also British Pathé, 'New Town 1959'.

73 EAFA, 'The Design of Space'. 
beds sometimes referred to as "coffins" owing to their dimensions". ${ }^{74} \mathrm{~A}$ 1969 film shows these grey 'coffins' planted with greenery but not adding a great deal of colour to the townscape. However, green spaces offered 'welcome relief' from buildings and traffic and the planners assumed high levels of municipal maintenance with 'The Design of Space' showing how the design of edgings could make maintenance, and especially mowing, easier. $^{75}$

Looking at films of the 1950s and 1960s, municipal planting in city centres gave the appearance of having been nationally agreed; cities as far apart as Luton and Hull displayed the same conical concrete planters with red tulips or red geraniums. ${ }^{76}$ Rectangular flower beds also featured in many city centres, often surrounding statues and planted with a limited range of plants and colours, usually red, pink, yellow and white, while beds of municipal roses were ubiquitous. ${ }^{77}$ The films and postcards of squares and precincts from this period show a decided trend towards the block planting of a solid mass of single colours and species of flowers producing almost architectural panels of colour in lawns of public buildings. As well as planned plants and lawns, florists and flower stalls added intense splashes of colour to the urban scene at market places and street corners. Indeed, the purchase of fashionable cut flowers for 'immediate and renewed consumption' was of necessity an urban habit, which has been compared to newspaper buying, and revealed the citizens' desire to possess colour every day. ${ }^{78}$

Art was an important aspect of material culture that introduced colour into city centre environments. In the period after 1945, public art became an integral part of the city centre landscape: '[it] came to be seen as a symbol of civic renewal and social progress. Sculpture and other types of works were commissioned for new public buildings and civic places, with the objective of bringing art to people's daily lives. ${ }^{79}$ These were often incorporated as part of shopping centres, walkways and underpasses and were also found inside buildings, visible to the street in glass-fronted modernist lobbies, and in popular locations like coffee bars. Civic art, especially murals and mosaics, could introduce large-scale colour images into some city centre landscapes. Pearson notes the high demand for murals, commenting that

${ }^{74}$ Sue Samme, 'Hemel Hempstead Town Centre Remembered', Our Dacorum, www.ourdacorum.org.uk/content/towns-and-villages/hemel-hempstead/dacorumu3a-university-of-the-third-age/changing-face-of-hemel-hempstead-number-13, accessed 21 Jun. 2017; 'Old Town Face Lift Aka Hemel Hempstead New Town, 1969', YouTube www.youtube.com/watch?v=boJHCnK51z0, accessed 21 Jun. 2017.

${ }^{75}$ EAFA, 'The Design of Space'.

76 'Luton 1960 Town Centre and Parade Old Cars, Marching', YouTube www.youtube.com/ watch?v=grGKVa8UNoI; 'Old Town Face Lift'; 'Hull 1959', YouTube www.youtube.com/ watch?v=5zqXhHFTJUY, accessed 21 Jun. 2017.

77 'Sheffield - City on the Move', www.youtube.com/watch?v=-v1-mT9afP4, accessed 5 Jul. 2017, 0:26; EAFA, 'The Design of Space'; British Pathé, 'New Town 1959'.

78 L.A. Kalba, 'Blue roses and yellow violets: flowers and the cultivation of colour in nineteenth-century France', Representations, 120 (2012), 83-114, at 84, 109.

79 G. Franklin, Post-War Public Art Protection, Care and Conservation (London, 2016), 6. 
an 'average of more than one substantial work per fortnight was installed in England during the 1950s and 1960s at a broad range of locations' ${ }^{80}$ The colourful public art works were either figurative in nature, like the one on the CWS building in Stevenage, or abstract, like Ray Howard Jones' 'An Eye for the People' mosaic on Cardiff's Western Mail building. The colours were usually primary or those used in the earlier twentiethcentury had palettes of primitivism or Fauvism; a tone or two removed from primary colours but still retaining a paint-box character. Many of these same colours were also used in decorative panels on modernist buildings, either in solid synthetic panels or as sections of single-toned tile mosaics. It is unusual to find public art of the 1950s and 1960s in pastel colours or delicate shades but William Mitchell's large-scale mural on the facade of Hull College (1962) is an exception, showing mathematical and scientific instruments in a range of soft greens and toning browns. ${ }^{81}$

Civic public art was generally popular but also sometimes controversial; there is no doubt that it caught the eye and city centre users responded to the work. In Coventry, the local paper reported on a new mosaic depicting the sixteenth-century Coventry Martyrs: 'It is only a fortnight since the mosaic was uncovered when Lord Silkin officially opened Broadgate House, in that short time a number of the pieces of brilliantly coloured stone have been chipped away. ${ }^{82}$ The large-scale mosaic was highly coloured with blues, greens and reds in rich hues reminiscent of illustrations found in medieval vellum manuscripts. The mosaic tiles themselves were reflective and the flame motifs around the outside of the image of the martyrs were edged with gold tiles, both adding to the bright and dazzling effect of the mosaic. What was originally thought to have been vandalism, or the local children's desire to possess the coloured parts, was possibly a technical problem with the attachment of the mosaic tiles. ${ }^{83}$

The limited and ephemeral nature of colour in the British city centre and the popular focus on bright colours as indicators of innovation, excitement and modernity posed problems for film makers. Newly equipped with mobile cameras and colour film in the 1960s, they were faced with daytime environments that were either still half built or old and grimy. Colour film makers found it hard to locate urban colour outside new towns and were drawn consistently to filming traditional urban markets. There are many examples of provincial markets filmed in both new and reconstructed town centres such as Norwich's traditional market place or Birmingham's nestled under the new Bull Ring. ${ }^{84}$ Market stalls tended

80 Pearson, Public Art, 10.

81 See David Hone's photograph on Flickr: www.flickr.com/photos/dhimages/609606954, accessed 5 Jul. 2017.

82 'Stones chipped off Broadgate House', Coventry Evening Telegraph, 16 May 1953, 7.

83 'Mosaic: pneumatic drills to blame?', Coventry Evening Telegraph, 7 Aug. 1953, 5.

84 For example: '1950's Norwich Part 4', YouTube www.youtube.com/watch? $\mathrm{v}=$ wQJxowxVW3Y; British Pathé, 'Bull Ring Centre Opened' (1964), YouTube www.youtube.com/watch?v=BRRspPXZTuQ, accessed 15 Jun. 2017, 0:36. 
to be filmed in the same manner, first from a high perspective which picked out the multicoloured awnings in the urban environment, and then from street level, showing the colourful details of stall and produce and often involving 'vox pops' with customers. Filming markets put colour, movement and 'real' people on the screen and offered a pleasant visual alternative to the traffic-choked streets of many town centres. ${ }^{85}$ Markets provided both the physical and metaphorical colour that was missing from many places; at the same time, film makers made it clear that these were enduring, 'traditional' activities rather than 'modern' ones. According to the Birmingham 1964 film commentary; 'the new centre finds room for the market stalls which every real housewife would hate to lose entirely'. ${ }^{86}$ As late as 1984, a promotional advertisement for Milton Keynes made the point that ordinary urban activities were accommodated in novel environments with the colour of the market awnings contrasted against a monotone built background. ${ }^{87}$ This focus on markets by film makers shows the enduring appeal of city centre markets even after modernization. The colourful, aromatic and noisy nature of markets lay at the heart of their enduring appeal.

Zybaczynski may have relegated everyday life to her final category, but we have found that colour in the post-war city centre was mainly a by-product of everyday human activity. ${ }^{88}$ Extensive examination of films and photographs of city centres in the 1940s, 1950s and 1960s reveals that physical colour was primarily manifest in the moveable material culture of urban life. It was vehicles, traffic control, crossings, lights, shop fronts and signs, advertising and clothing which added the most intense colour to the city landscape. Green featured in the landscaped environment in the form of trees and grass verges and occasional examples of integrated artworks brought colour to the urban landscape but these were far more prevalent in new town or reconstructed city centres. Cardiff's now-demolished Western Mail mosaic or infill buildings with coloured panels such as the extant Britannic House in Peterborough or the former Maple's department store still to be seen in Leicester were unusual, even if representative of their era.

\section{The experience of colour and its significance}

This third strand examines how colour contributes to the urban attachments of the town user and dweller. Specific colours help to form a sense of belonging to a place. On one level, traditional building materials vary between regions and towns and contribute to a sense of distinct place and belonging. Oxford is a famous example of this with its yellow

${ }^{85}$ Huntley Film Archives, 'Shopping Centre Opening - 1960s', www.youtube.com/watch? v=ltwzI-NzQF0, accessed 26 Apr. 2017.

86 'Bull Ring Centre Opened', 0:36.

${ }^{87}$ Milton Keynes 'Red Balloon', YouTube advertisement www.youtube.com/watch?v= EOC8wtkzcrk, accessed 15 Jun. 2017.

88 Zybacynski, 'Colour-important factors in preserving the local identity', 88-9. 
ochre tones resulting from a soft climate and the local stone, while Leicester's red bricks and the pale sandstone of Edinburgh's new town are equally characteristic of locale. ${ }^{89}$ The individual experience of colour, however, is subjective and people's experience and understanding of colour is culturally constructed: the experience of colour is fluid and may be particular to different localities and different periods. ${ }^{90}$ In his work on colour in medieval Venice, Paul Hills asks the important question of whether colour plays 'any role in the subject's sense of being at home within his social space?'91 Andrew Jones and Gavin MacGregor agree that while colour vision is 'an integral attribute', it needs to be considered in 'its lived and its social dimensions' ${ }^{92}$ Linguistic analyses tend to overlook this element of colour, arguing that colour categories are universal because they are fixed neurophysiologically. ${ }^{93}$

This section draws on various forms of reminiscence data, including social media. Accessing people's responses to physical colour in the past is challenging because references to encounters with colour are fleeting. However, reminiscences are invaluable for providing insight, albeit retrospectively, into people's different interactions with, and emotional responses to, colour in their environment. The degree of detail in the memories can be unexpectedly specific and enlivening, showing aspects of the town centres which may have otherwise gone unnoticed. They bring out the minutiae of everyday urban colour while also revealing the different significances that colour had for individuals. Thus, colour is not just a physical visual sensory experience but colours also carry messages and values.

Extensive viewing of colour film and photographs of British city centres shows that there was a national language of colour operating in the urban environment. Blue police boxes and red telephone and post boxes indicated safety, assistance and communications, as well as adding colour to the pavements. While these could be rural too, other aspects of national colour were specifically urban. The fascia of national chains of shops, particularly the red of Woolworth signs and the green and gold of Marks and Spencer appeared at different scales in various localities and were recognized by all. Even today on nostalgia message boards, posters provide directions to long-vanished shops and clubs using these stores as landmarks. Sometimes colour and form merged unconsciously to the point where difference or departures from the established combinations jarred on the observer. A contributor on a Sheffield forum posted:

89 T. Porter, Colour Outside (London, 1982), 37.

90 Hills, Venetian Colour, 18, 186.

91 Ibid., 18.

92 A. Jones and G. MacGregor, 'Introduction: wonderful things - colour studies in archaeology from Munsell to materiality', in A. Jones and G. MacGregor (eds.), Colouring the Past: The Significance of Colour in Archaeological Research (Oxford, 2002), 1-22, at 6.

93 See B. Berlin and P. Kay, Basic Color Terms: Their Universality and Evolution (Berkeley, 1969), discussed in Jones and MacGregor, 'Introduction', 4-5. 
I don't remember Sheffield police boxes being anything but green and white. In the mid sixties there used to be one on Buchanan Road..., and that was definitely green and white. I remember as a child wondering why it was the wrong colour, because I thought that all police boxes should be blue, like Dr Who's Tardis! ${ }^{94}$

One remaining green and white police box is preserved on Surrey Street in Sheffield. Irish immigrants found the British red post boxes 'different and foreign', as one of the first actions of the Irish Free State government had been to paint the post boxes green. ${ }^{95}$ Hull's cream Gilbert Scott telephone boxes dating from the 1950s catch the eye, even in black and white photographs: they are symbolic of place and visitors are still offered explanations for their difference. ${ }^{96}$

In addition to this national understanding of colour, there was also a local dimension to the significance and meaning of particular colours as Hull's telephone and Sheffield's police boxes show. Bus colour seems to have contributed significantly to a sense of belonging to towns and cities and helped to make residents feel 'at home'. They offered a particularly distinctive experience because of the varied combinations of colours, which did not necessarily reflect a town's heraldic colours. The colours of public transport in the urban environment are most likely to be recalled because it was important to differentiate between bus companies; this was particularly the case for children and school buses. Rob Haywood recounts how, in the 1950s, he felt most at home on Leicestershire's Midland Red buses though he also used the maroon and cream Corporation buses of Leicester city. Having travelled to Grantham on a green bus, he recalled the relief on returning to Leicester bus station 'where there were more buses than you could shake a stick at. And joy of joys, most of them were red! ${ }^{\prime 97}$ Here, colour related to a place-specific experience and contributed to a sense of 'being at home' in the city centre. ${ }^{98}$

Clothes and personal possessions featured frequently in memories of the city centre. The rich nature of individual testimony gives us an insight into the detail and meaning of urban colour and colour choices. In 1960s Birmingham, Andrew Eves 'had just left school so every Monday without fail dressed in my winkle picker shoes, Italian styled mod suit and bright red narrow tie of course (and we thought we were the Bees Knees)'. ${ }^{99}$ Patricia Rose recounts a similar experience: 'I thought I was the bees knees

94 'Earthboy', Sheffield History, www.sheffieldhistory.co.uk/forums/topic/46-the-blue39police-box39-next-to-the-town-hall/?page=4, accessed 30 Apr. 2017.

95 Quoted in E. Delaney, The Irish in Post-War Britain (Oxford, 2007), 59.

96 ' 8 Beautiful Old Pictures of Hull at Christmas', HEYtoday.co.uk, www.heytoday. co.uk/local-news/8-beautiful-old-pictures-of-hull-at-christmas/, accessed 30 Apr. 2017; Visit Hull http://visithull.org.uk/wp-content/uploads/2016/01/Hulls-Creamphone-boxes-1-1.pdf, accessed 19 Jul. 2017.

97 Haywood, 'On the Buses - Early Days'.

98 Hills, Venetian Colour, 18.

99 Andrew Eves, 'Birmingham in the 1960s', Retrowow: your guide to vintage and retro www.retrowow.co.uk/retro_britain/town_centres/birmingham_60s.html, accessed 12 Oct. 2016. 
in my polka dot skirt, white blouse with matching neckerchief round my neck, black flatties, one sock green and one sock pink, and of course my gorgeous beehive. ${ }^{100}$ Both teenagers dressed up in order to go into the city centre whether for work or play and made conscious colour choices in their clothing.

Clothing played a role in the sense of belonging on the city centre stage. Football bobble hats and scarves started to appear in photographs of football spectators more frequently from the 1950s. From the 1970s, further items of clothing such as shirts and track suits were produced in local team colours. ${ }^{101}$ These splashes of team colour, which often appeared in town centres only on match day, helped to connect particular colours to place. Other identifiers of place produced less of an impact as they were sported by smaller sub-groups of the population. In 1958, Leicester University student Colin Miller's 'first trip into the city centre was to buy a University scarf from Knight's Outfitters in Granby Street, the claret, white and green striped scarf was an essential article of clothing for most first year students and one which emphatically declared "look at me, I am a university student", one of the elite five per cent'. ${ }^{102}$ The colours of the scarf indicated he was not just any 'university student', but he was a Leicester University student. Another example was the green 'parka' worn by Bristol boys in the mid-1960s. It was 'made of a light canvas looking material, loose fitting which dipped at the back with a hood. Around the hood would be fur (from granny's old coat, if she'd let you have it) and on the back written in bold white letters was the name of our city BRISTOL. ${ }^{\prime 103}$ These examples of town-specific sub-identities illustrate how the wearing of particular colours signified belonging to a recognizable sector of the local urban community.

Using digital social media for research can bring out the unexpected (and perhaps unintentional) detail of urban colour. Sue from Hemel Hempstead recalled the unintended colour on the walls of a circular car park which had 'lots of rainbow colours on each bend where cars had scratched their paintwork'. ${ }^{104}$ This detail of colour demonstrates how reminiscences can bring out the minutiae of urban colour experience and enables us to remember the colour that was less likely to be recorded at the time. Reminiscences also reveal transitory colour, sometimes only experienced for moments or minutes at a time; for example, the discolouration of the buses, the marks on the walls where the cars had scratched their paint. Despite this transience, these experiences are

100 Patricia Rose, ibid.

101 MACE, 'Jaywalking: Shouts for City' (1975), ATV Regional Programme, presented by Sue Jay.

102 C. Miller, A Degree of Swing: Lessons in the Facts of Life: Leicester 1958-64 (Derby, 2012), 36.

103 'Pauline', '60s Fashion and Style', Retrowow www.retrowow.co.uk/retro_style/60s/60s_ fashion.html, accessed 12 Oct. 2016.

104 Sue, 'Memories of Hemel Hempstead in the 1970s', Flibbertigibbet http:/ / cyberelk.net/ sue/2007/02/27/hemel-hempstead/comment-page-1/, accessed 25 Jan. 2017. 
recalled with a powerful accuracy decades later and can have a real emotional significance. To return to Hills, the experience of colour formed an important part of the everyday collective urban experience, but also of individual or 'tribal' identities. ${ }^{105}$

\section{Conclusion}

Researching the historic visual experience of physical colour undoubtedly presents a range of challenges. However, our research has shown that the experience of physical colour enabled people to navigate the post-war city. Colour drew them into shops and markets, signalled the proximity of landmark stores, flagged safe places to cross and indicated the means of communication with red post and telephone boxes. Citizens could have a shared national collective understanding of colour as shown by orange Belisha Beacons and Woolworth's red fascia. The understanding of the materiality of colour, equally and simultaneously, was used to construct people's sense of ownership and identity. Colour could be 'decoded' on a city basis: bus liveries possessed a colour significance dependent upon locality. Moreover, people played an active role in building this identity through their wearing of football colours or donning of university scarves. Using social media for research showed us that people's visual urban memories were strong and long-lasting, even if occasionally muddled and contested. Colours of clothing and transport were recalled with particular accuracy in forum posts and testimonies, as were certain shop signs. The experience of colour was a significant contributory factor in constructing a sense of urban belonging.

A surprising outcome of this research was that, despite the availability of new materials with the possibilities of bright colour, the post-war built urban environment did not in itself become significantly more colourful across the period. Infrastructural and material developments such as buildings, lighting, flora and advertising provided some colour, but it was the manifestations of everyday human activities that caught the eye in the city. In clothing, vehicles, markets and movements, urban life was colourful and full of colour choices. In this respect, the post-war British city centre had much in common with the classical or medieval city. Modern urban historians should not only look at the urban landscape but learn to see it in colour.

105 Hills, Venetian Colour. 